Mots. Les langages du politique

102 | 2013

Les discours sur l'enseignement supérieur et la recherche

\title{
Sarah Leroy
}

Valérie Bonnet

\section{(2) OpenEdition}

Journals

Édition électronique

URL : http://journals.openedition.org/mots/21242

DOI : $10.4000 /$ mots. 21242

ISSN : 1960-6001

Éditeur

ENS Éditions

Édition imprimée

Date de publication : 2 septembre 2013

ISBN : 978-2-84788-414-2

ISSN : 0243-6450

\section{Référence électronique}

Valérie Bonnet, «Sarah Leroy », Mots. Les langages du politique [En ligne], 102 | 2013, mis en ligne le 02 septembre 2013, consulté le 15 septembre 2020. URL : http://journals.openedition.org/mots/21242 


\section{Sarah Leroy}

Notre consœur Sarah Leroy nous a quittés le 8 février.

Spécialiste incontestée du nom propre, cette chercheuse de haut niveau affectionnait tout particulièrement les objets singulièrement abstraits qui représentaient une forme de défis intellectuels, sans que pour autant sa réflexion abandonne toute dimension opératoire, puisqu'elle collaborait à l'Information grammaticale, La revue française de linguistique appliquée ou avait participé à des projets orientés vers l'enseignement, comme en témoigne sa contribution dans Les variétés du français parlé dans l'espace francophone : ressources pour l'enseignement. Travailleuse inlassable, elle a laissé un corpus de textes impressionnant(s), traitant de l'antonomase du nom propre, son sujet de thèse, comme de la déonomastique ou de l'étymologie, extrema d'un cheminement passé par la métaphore, la comparaison, le dialogisme, non sans quelques détours par l'oralité, l'ordre des mots... Elle a posé son regard rigoureux et clairvoyant sur des domaines disciplinaires aussi divers que la sémantique, la syntaxe, la morphologie, la sociolinguistique, la lexicologie, la didactique, l'analyse de discours, proposant des avancées tant théoriques que méthodologiques.

Chargée de recherche au CNRS au laboratoire MoDyCo, elle a débuté son parcours au sein de notre communauté à l'université de Montpellier 3, où elle avait suivi une formation en lettres et linguistique, puis enseigné, avant de rejoindre l'université de Bretagne occidentale pour sa seconde année en tant qu'attachée temporaire d'enseignement et de recherche. Elle a conservé de cette expérience une réelle prédilection pour la transmission des savoirs, acceptant les charges de cours qui lui étaient proposées, à Paris, à Bâle ou au sein de l'École doctorale algéro-française. Ce double investissement dans la recherche et l'enseignement ne l'a pas pour autant empêchée d'occuper des responsabilités administratives, au comité national du CNRS en tant qu'élue syndicale, dans les commissions de spécialistes, puis les comités de sélection des universités, et dans l'administration de son laboratoire, dont elle était directrice adjointe.

Exigeante envers les autres comme envers elle-même, elle a communiqué ce sens de l'engagement au sein du collectif à ceux qui ont eu la chance de la côtoyer, qu'il s'agisse des jeunes chercheurs de sa génération ou de celles qui lui ont lui ont succédé. Elle n’hésitait pas à les accompagner et épauler, de manière informelle, comme elle devait le faire en tant que directrice de 
thèse, puisqu'elle venait de soutenir brillamment son habilitation à diriger les recherches sur les aspects linguistiques du processus cognitif général de l'évaluation orientée vers le plus haut degré. Cette émulation, elle a su la favoriser à une époque où la recherche individuelle était de mise dans nos disciplines, initiant des projets, proposant des collaborations à ses pairs ou ses cadets. Elle qui disait d'elle-même qu'elle ne voulait pas être l'incarnation de l'antonomase du nom propre se proposait toujours d'explorer de nouvelles voies, au gré de ses coopérations et de ses rencontres, investie dans divers projets dépassant amplement les frontières françaises, voire européennes.

D'un humour ravageur, voire provocateur, elle aimait les titres dérangeants ("Sale comme un peigne et méchant comme une teigne»), les formules grinçantes («D’un torrent de larmes à un Himalaya de bêtise»), ou élégantes ("Changement du nom, changement de noms, changement des noms»), les signatures poétiques (Leroy \& Loiseau), les jeux de langage ( On emprunte bien les noms propres»), les postures iconoclastes comme tremper ses pieds dans une fontaine à l'issue d'un colloque fort sérieux sur l'intensité, la comparaison et le degré.

Forte personnalité, pugnace dans les débats scientifiques comme académiques, elle a laissé notre communauté orpheline d'une brillante chercheuse, pour laquelle la collocation service public ne s'est jamais désémantisée, et celle-ci, se reconnaissant dans ce parangon, lui a rendu un hommage unanime.

Valérie Bonnet, avec l'amical soutien d'Agnès Steuckardt 